\title{
Suscetibilidade à contaminação da água subterrânea em função de propriedades dos solos no Cerrado brasileiro
}

\author{
Rafael Mingoti( ${ }^{(1)}$, Claudio Aparecido Spadotto(1) e Diego Augusto de Campos Moraes ${ }^{(2)}$ \\ (1)Embrapa Gestão Territorial, Avenida Soldado Passarinho, no 303, Fazenda Chapadão, CEP 13070-115 Campinas, SP, Brasil. E-mail: \\ rafael.mingoti@embrapa.br, claudio.spadotto@embrapa.br (2)Universidade Estadual Paulista, Rua José Barbosa de Barros, № 1.780, \\ Fazenda Lageado, CEP 18610-307 Botucatu, SP, Brasil. E-mail: die.gomoraes45@gmail.com
}

Resumo - O objetivo deste trabalho foi apresentar um índice para caracterização da suscetibilidade dos solos à contaminação do lençol freático, bem como realizar um estudo de caso exploratório para os solos do bioma Cerrado. $\mathrm{O}$ índice de tempo de retenção (TR) de água nos solo foi determinado a partir de valores médios, obtidos por meio de uma metodologia de filtragem, em bases de dados das seguintes propriedades do solo: espessura de horizontes; granulometria; teor de carbono orgânico; densidades global e de partículas; e umidade na capacidade de campo. A profundidade do lençol freático foi estimada com uso do modelo Hand. As distribuições espaciais dos dados de entrada e dos resultados do índice TR foram obtidas com uso de um aplicativo de sistema de informação geográfica. Os solos que oferecem menor proteção à contaminação do lençol freático por contaminantes químicos orgânicos estão localizados nas regiões Sudeste e Centroleste do Mato Grosso, no Oeste da Bahia, no Sudoeste de Goiás e no Norte de Mato Grosso do Sul. Os solos predominantes nas áreas mais suscetíveis são Neossolos Quartzarênicos órticos e Latossolos Vermelhos distróficos.

Termos para indexação: gestão territorial, ocupação do solo, poluição do solo, recursos hídricos, serviço ecossistêmico, sistema de informação geográfica.

\section{Groundwater contamination susceptibility as a function of soil properties in the Brazilian Cerrado}

\begin{abstract}
The objective of this work was to present an index for the characterization of soil susceptibility to groundwater contamination, as well as to perform an exploratory study of the soils from the Brazilian Cerrado biome. The water retention time (RT) index was determined with mean values obtained from a filtering methodology, in databases of the following soil properties: depth of the horizons; granulometry; organic carbon content; bulk density and particle density; and moisture content at field capacity. The water table depth was estimated using the Hand model. Spatial distributions of input data and TR index results were obtained using a geographic information system software. Soils that offer low protection to groundwater contamination by organic chemicals are located in southeast and east-central regions of the state of Mato Grosso, in the western of the state of Bahia, in the south of Goiás, and in the north of Mato Grosso do Sul, Brazil. The predominant soil classes in the more susceptible areas are "Neossolos Quartzarênicos órticos" (Entisols) and "Latossolos Vermelhos distróficos" (Oxisols).
\end{abstract}

Index terms: territorial management, land cover, soil pollution, water resources, ecosystem services, geographic information system.

\section{Introdução}

A função de filtragem do solo é um importante serviço ecossistêmico para a proteção das águas subterrâneas e superficiais (Keesstra et al., 2012). Segundo Souza (2009), o solo atua como filtro natural de poluentes e serve como meio para os processos de sorção e degradação desses poluentes. As propriedades dos solos influem marcadamente no grau de vulnerabilidade de corpos de água subterrânea à contaminação (Weber \& Weed, 1974; Racke et al., 1997; Futch \& Singh, 1999).
A vulnerabilidade de aquíferos à poluição é um conceito inverso ao da capacidade de assimilação de cargas contaminantes pelos corpos d'água, com a diferença adicional de que o aquífero possui uma cobertura não saturada que proporciona mais proteção (Foster et al., 1988).

O planejamento e a gestão de uso e ocupação do solo por meio da restrição e da fiscalização das atividades antrópicas é uma estratégia eficaz para proteção de águas subterrâneas (Brollo et al., 2000). Esse planejamento pode ter foco na proteção geral de 
um aquífero específico, com identificação de áreas mais vulneráveis à contaminação, sobretudo em zonas de afloramento (Foster et al., 2002; Hirata et al., 2010).

A utilização de agroquímicos, como fertilizantes e agrotóxicos, na agricultura tem potencial impacto sobre a saúde humana e os organismos, nos diferentes compartimentos ambientais (Spadotto \& Gomes, 2006). A lixiviação de solutos - especialmente nutrientes, metais pesados e agrotóxicos - destaca-se entre os processos de transporte nos diferentes compartimentos ambientais. Portanto, em solos sob intensivo uso agrícola, a necessidade de monitoramento constante da qualidade das águas é maior (Dellamatrice \& Monteiro, 2014).

A intensa utilização de agrotóxicos pelas grandes culturas, a ocorrência frequente de solos de textura arenosa e média no Cerrado (Goedert, 1987) e a utilização de água proveniente de aquíferos não confinados para abastecimento público, em áreas desse bioma (Dores et al., 2008), tornam evidente a necessidade da utilização adequada e criteriosa de agrotóxicos, bem como a importância da identificação de áreas vulneráveis à contaminação.

Existem diversos índices de vulnerabilidade à contaminação de corpos d'água subterrâneos por agrotóxicos (Gomes et al., 2006); entretanto, para que esses índices possam ser utilizados na avaliação de áreas específicas, é necessário levar em conta características de cada agrotóxico, o que traz complexidade à avaliação. Além disso, esses índices demandam diversos dados de entrada, o que limita ainda mais a sua utilização. Contudo, em estudos de maior abrangência geográfica, em escala menor, alguns dados de entrada podem ser obtidos remotamente, com posterior integração em um sistema de informações geográficas (SIG) (Budiman et al., 2003; Spadotto et al., 2012).

A profundidade de lençol freático é uma informação importante na determinação da vulnerabilidade de corpos de água subterrâneos à contaminação. A sua obtenção requer a utilização de sondagens a campo (Mingoti, 2012); entretanto, pode ela ser estimada por meio da utilização do modelo "Height Above the Nearest Drainage" (Hand), ou Altura Acima da Drenagem mais Próxima, que utiliza a diferença entre a altitude extraída de modelos digitais de elevação (DEM) e a rede de drenagem de referência para calcular alturas relativas, que possuem correlação com a profundidade do lençol freático e com a topografia do terreno (Nobre et al., 2011).
O objetivo deste trabalho foi apresentar um índice para caracterização da suscetibilidade dos solos à contaminação do lençol freático, baseado em diversas propriedades dos solos, bem como realizar um estudo de caso, em escala exploratória com o SIG, para a área do bioma Cerrado.

\section{Material e Métodos}

Para caracterizar a susceptibilidade da água subterrânea à contaminação, entendida como o inverso da proteção que os solos oferecem, foi desenvolvido o índice de Tempo de Retenção (TR) de água nos solos, com base no conceito de tempo de convecção ou de percurso (Davidson et al., 1968; Rao et al., 1985; Spadotto et al., 2012), apresentado na seguinte expressão: $\mathrm{TR}=(\mathrm{L} \times \mathrm{FC} / \mathrm{Q}) \times \mathrm{RF}$, em que $\mathrm{L}$ é a profundidade do lençol freático ou aquífero $(\mathrm{cm})$; FC é a umidade do solo na capacidade de campo $\left(\mathrm{cm}^{3} \mathrm{~cm}^{-3}\right)$; Q é a recarga hídrica líquida $\left(\mathrm{cm} \mathrm{ano}^{-1}\right)$ e RF é o fator de retardamento do movimento do contaminante no solo. Esse fator refere-se a contaminantes químico-orgânicos $\left(\mathrm{RF}_{\mathrm{QO}}\right)$ e pode ser obtido a partir da seguinte expressão: $\mathrm{RF}_{\mathrm{QO}}=1+\mathrm{BD} \times \mathrm{OC}_{\mathrm{x} \mathrm{K}} \mathrm{OC} / \mathrm{FC}$; em que BD é a densidade global do solo $\left(\mathrm{g} \mathrm{cm}^{-3}\right)$; OC é o teor de carbono orgânico do solo $\left(\mathrm{g} \mathrm{g} \mathrm{g}^{-1}\right)$ e $\mathrm{K}_{\mathrm{OC}}$ é o coeficiente de sorção normalizado para $\mathrm{OC}\left(\mathrm{cm}^{3} \mathrm{~g}^{-1}\right)$. Assim, o valor numérico do índice é inversamente proporcional à suscetibilidade do corpo de água subterrâneo à contaminação.

$\mathrm{O}$ estudo de caso foi realizado de maneira espacializada, em escala exploratória, tendo-se adotado os seguintes critérios: região - bioma do Cerrado no Brasil (IBGE, 2004); escala do mapa de solos - 1:5.000.000 (Santos et al., 2011); valores médios de FC, BD e OC, para os horizontes A e para os horizontes diagnósticos $\mathrm{B}$ ou $\mathrm{C}$, de cada tipo de solo presente no mapa utilizado.

A determinação do RF foi feita para um contaminante químico-orgânico $\left(\mathrm{RF}_{\mathrm{QO}}\right)$ hipotético, com valor de $\mathrm{K}_{\mathrm{OC}}=1 \mathrm{~cm}^{3} \mathrm{~g}^{-1}$.

Para obtenção dos valores médios de espessura dos horizontes, e de FC, BD e OC, utilizaram-se os bancos de dados de informações de solos de Cooper et al. (2005) e de Oliveira et al. (2008). No primeiro banco de dados, obtiveram-se os dados de OC, enquanto, no segundo, obtiveram-se os valores de $\mathrm{BD}$ e espessura dos horizontes.

Pesq. agropec. bras., Brasília, v.51, n.9, p.1252-1260, set. 2016 DOI: 10.1590/S0100-204X2016000900025 
Os valores de FC não constavam em nenhum dos bancos de dados analisados. Com isso, optou-se pela estimativa do parâmetro por meio das funções de pedotransferência apresentadas em Tomasella et al. (2000). Essas funções, no entanto, necessitam de parâmetros de retenção de água nos solos, os quais foram estimados por meio do software Qualisolo (Naime et al., 2006), a partir dos valores médios de granulometria (\%) e de densidade de partículas $\left(\mathrm{g} \mathrm{cm}^{-3}\right)$ obtidos no banco de dados de Oliveira et al. (2008). Ressalta-se que há propagação de erros (Budiman et al., 2003) nas diferentes etapas desse procedimento (valores médios de granulometria e densidade de partícula por tipo de solo, estimativa de parâmetros de retenção de água no solo e estimativa de valores de FC), o que demanda novos trabalhos com metodologias específicas para se estimar esses parâmetros.

Os valores médios dos atributos necessários (espessura dos horizontes, BD, OC, granulometria e densidade de partículas) foram obtidos por meio de um processo de filtragem, em ambos os bancos de dados, com uso do aplicativo Microsoft Excel. Primeiramente, foram removidos os dados que apresentavam valor zero ou nulo para ao menos um dos atributos necessários. Em seguida, foram removidos dados que geralmente não são encontrados em solos minerais (Kiehl, 1979), para evitar erros grosseiros. No caso de BD, foram removidos os valores menores do que $0,8 \mathrm{~g} \mathrm{~cm}^{-3} \mathrm{e}$ maiores do que $2,0 \mathrm{~g} \mathrm{~cm}^{-3} \mathrm{e}$, para densidade de partículas, foram removidos os valores menores do que $2,0 \mathrm{~g} \mathrm{~cm}^{-3} \mathrm{e}$ maiores do que $3,0 \mathrm{~g} \mathrm{~cm}^{-3}$.

Após o processo de remoção de dados, realizouse uma segunda etapa de filtragem, que consistiu em selecionar apenas dados de solos que apresentavam classificação pontual do perfil amostrado igual à classe apresentada no mapa de solos; ou seja, os dados foram filtrados espacialmente de acordo com a classe de solos do mapa e do perfil amostrado. Nessa etapa, utilizouse a correlação da classificação dos solos no terceiro nível do Sistema Brasileiro de Classificação de Solos como critério (Santos et al., 2006).

Para classes de solos que não tiveram nenhum dado selecionado após a filtragem espacial, adotou-se o critério de utilizar todos os dados da referida classe, localizados ao longo da área de estudo. Para as classes de solos que, mesmo na condição anterior, não tiveram nenhum dado selecionado, utilizaram-se todos os dados da referida classe nos bancos de dados, mesmo tendo-se ciência das diferentes características climáticas e de cobertura da terra de outros biomas (Demattê \& Demattê, 1993).

A recarga hídrica líquida anual para a área de estudo foi estimada pela diferença entre as médias históricas de chuva (Alvares et al., 2015) e a evapotranspiração (Alvares et al., 2013) nos meses entre outubro e março. Esse critério foi adotado porque, na área de estudo, essa é a época do ano em que a atividade agrícola ocorre de maneira mais expressiva, e, além disso, ocorrem maiores volumes de chuvas do que de evapotranspiração, o que proporciona maior risco de lixiviação de contaminantes. Não se verificou, neste estudo, o efeito que a irrigação pode ter sobre o índice TR.

A profundidade do lençol freático foi estimada por meio da aplicação do modelo Hand (Nobre et al., 2011), nos dados do DEM do projeto Shuttle Radar Topographic Mission, SRTM, disponibilizados pelo United States Geological Survey (USGS), em seu sítio na internet, em formato raster com resolução espacial de $90 \mathrm{~m}$.

Os valores finais de profundidade do lençol freático foram obtidos pela limitação dos valores do Hand a, no máximo, o valor da espessura do solo com maior soma de espessuras dos horizontes A e B (ou C). Essa etapa é necessária para evitar valores muito altos de profundidade do lençol freático.

Todos os dados de entrada foram convertidos para formato raster, com resolução espacial de $100 \mathrm{~m}$, que é a resolução espacial fornecida para evapotranspiração, no sistema de referência Sirgas 2000 e no sistema de projeção Policônica, com uso do aplicativo de sistemas de informação geográfica (SIG) Esri ArcGis. O processamento das equações e a obtenção dos resultados foram feitos com uso dos padrões de resolução espacial, dos sistemas de referência e de projeção mencionados.

\section{Resultados e Discussão}

Os valores médios dos atributos necessários para a aplicação do índice TR, selecionados por meio de filtragem, estão apresentados na Tabela 1. Os seguintes perfis de solos não foram encontrados na área do Cerrado: Luvissolos Crômicos órticos, Luvissolos Crômicos pálicos, Planossolos Háplicos distróficos, Planossolos Háplicos eutróficos, Vertissolos Ebânicos órticos e Vertissolos Háplicos órticos. Com isso, os valores dos parâmetros obtidos para essas classes de solos devem ser utilizados com cautela, devido às 
Tabela 1. Valores médios dos atributos das classes de solos da área de estudo, obtidos por filtragem nas bases de dados.

\begin{tabular}{|c|c|c|c|c|c|c|c|c|c|}
\hline \multirow[t]{2}{*}{ Classe de solo } & \multirow[t]{2}{*}{ Horizonte } & $\begin{array}{l}\text { Espessura } \\
(\mathrm{cm})^{(4)}\end{array}$ & Argila & Silte & Areia & \multirow[t]{2}{*}{$\begin{array}{c}\mathrm{OC} \\
\left(\mathrm{g} \mathrm{g}^{-1}\right)^{(5)}\end{array}$} & $\begin{array}{l}\text { Densidade de } \\
\text { Partículas }\end{array}$ & $\begin{array}{l}\text { Densidade } \\
\text { do Solo }\end{array}$ & \multirow{2}{*}{$\begin{array}{c}\text { Umidade } \\
\text { na CC } \\
\left(\mathrm{cm}^{3} \mathrm{~cm}^{-3}\right)\end{array}$} \\
\hline & & & \multicolumn{3}{|c|}{-------- $(\%)^{(4)}$--------- } & & ------- $(\mathrm{g} \mathrm{cm}$ & $\left.\mathrm{n}^{-3}\right)$------- & \\
\hline Argissolos Vermelhos distróficos ${ }^{(2)}$ & A & 46,00 & 14,89 & 10,64 & 74,48 & 0,036 & 2,60 & 1,45 & 0,20 \\
\hline Argissolos Vermelhos distróficos ${ }^{(2)}$ & B & 300,00 & 24,85 & 11,64 & 63,52 & 0,003 & 2,60 & 1,41 & 0,24 \\
\hline Argissolos Vermelhos eutróficos ${ }^{(2)}$ & A & 45,00 & 36,97 & 29,23 & 33,80 & 0,023 & 2,37 & 1,26 & 0,34 \\
\hline Argissolos Vermelhos eutróficos ${ }^{(2)}$ & B & 220,00 & 49,07 & 25,21 & 25,72 & 0,005 & 2,54 & 1,32 & 0,37 \\
\hline Argissolos Vermelho-Amarelos distróficos ${ }^{(1)}$ & A & 40,00 & 25,91 & 16,62 & 57,47 & 0,011 & 2,54 & 1,38 & 0,26 \\
\hline Argissolos Vermelho-Amarelos distróficos ${ }^{(1)}$ & B & 160,00 & 39,22 & 16,02 & 44,77 & 0,003 & 2,61 & 1,40 & 0,30 \\
\hline Argissolos Vermelho-Amarelos eutróficos ${ }^{(1)}$ & A & 40,00 & 16,83 & 40,67 & 42,50 & 0,013 & 2,54 & 1,38 & 0,31 \\
\hline Argissolos Vermelho-Amarelos eutróficos ${ }^{(1)}$ & B & 150,00 & 39,56 & 36,56 & 23,89 & 0,003 & 2,61 & 1,43 & 0,37 \\
\hline Cambissolos Háplicos Ta eutróficos ${ }^{(1)}$ & A & 15,00 & 51,00 & 32,00 & 17,00 & 0,026 & 2,67 & 1,56 & 0,36 \\
\hline Cambissolos Háplicos Ta eutróficos ${ }^{(1)}$ & B & 40,00 & 39,00 & 44,00 & 17,00 & 0,006 & 2,69 & 1,61 & 0,34 \\
\hline Cambissolos Háplicos Tb distróficos ${ }^{(1)}$ & A & 29,00 & 33,68 & 32,08 & 34,24 & 0,014 & 2,60 & 1,00 & 0,39 \\
\hline Cambissolos Háplicos Tb distróficos ${ }^{(1)}$ & $\mathrm{C}$ & 180,00 & 17,10 & 45,76 & 37,14 & 0,003 & 2,66 & 1,35 & 0,36 \\
\hline Cambissolos Húmicos distróficos ${ }^{(2)}$ & A & 110,00 & 28,83 & 30,30 & 39,30 & 0,032 & 1,89 & 0,46 & 0,41 \\
\hline Cambissolos Húmicos distróficos ${ }^{(2)}$ & $\mathrm{C}$ & 165,00 & 28,40 & 21,90 & 49,70 & 0,010 & 2,50 & 0,83 & 0,34 \\
\hline Chernossolos Argilúvicos órticos ${ }^{(2)}$ & A & 40,00 & 46,30 & 30,40 & 23,30 & 0,033 & 2,57 & 1,40 & 0,37 \\
\hline Chernossolos Argilúvicos órticos ${ }^{(2)}$ & B & 110,00 & 46,00 & 30,53 & 23,48 & 0,005 & 2,60 & 1,30 & 0,40 \\
\hline Chernossolos Rêndzicos órticos ${ }^{(2)}$ & A & 55,00 & 33,00 & 37,00 & 30,00 & 0,042 & 2,70 & 1,31 & 0,39 \\
\hline Chernossolos Rêndzicos órticos ${ }^{(2)}$ & $\mathrm{C}$ & 80,00 & 36,00 & 35,00 & 29,00 & 0,004 & 2,70 & 1,41 & 0,37 \\
\hline Gleissolos Háplicos Tb distróficos ${ }^{(2)}$ & A & 37,00 & 37,75 & 19,50 & 42,75 & 0,034 & 2,04 & 0,60 & 0,39 \\
\hline Gleissolos Háplicos Tb distróficos ${ }^{(2)}$ & $\mathrm{C}$ & 155,00 & 55,00 & 14,50 & 30,50 & 0,004 & 2,39 & 1,03 & 0,41 \\
\hline Gleissolos Sálicos aódicos ${ }^{(2)}$ & A & 15,00 & 53,50 & 27,00 & 19,50 & 0,029 & 2,27 & 1,60 & 0,26 \\
\hline Gleissolos Sálicos aódicos ${ }^{(2)}$ & $\mathrm{C}$ & 110,00 & 24,60 & 10,80 & 64,60 & 0,010 & 2,42 & 1,48 & 0,21 \\
\hline Latossolos Amarelos sistróficos ${ }^{(1)}$ & A & 20,00 & 20,60 & 4,20 & 75,20 & 0,010 & 2,61 & 1,24 & 0,14 \\
\hline Latossolos Amarelos sistróficos ${ }^{(1)}$ & B & 170,00 & 29,40 & 4,40 & 66,20 & 0,002 & 2,65 & 1,38 & 0,18 \\
\hline Latossolos Vermelho-Amarelos sistroférricos ${ }^{(2)}$ & A & 70,00 & 59,75 & 14,25 & 26,00 & 0,030 & 2,80 & 1,01 & 0,47 \\
\hline Latossolos Vermelho-Amarelos sistroférricos ${ }^{(2)}$ & B & 195,00 & 62,40 & 10,00 & 27,60 & 0,006 & 2,88 & 1,11 & 0,45 \\
\hline Latossolos Vermelho-Amarelos distróficos ${ }^{(1)}$ & A & 48,00 & 30,26 & 9,85 & 59,89 & 0,017 & 2,50 & 1,24 & 0,25 \\
\hline Latossolos Vermelho-Amarelos distróficos ${ }^{(1)}$ & B & 290,00 & 38,69 & 10,48 & 50,83 & 0,005 & 2,55 & 1,27 & 0,28 \\
\hline Latossolos Vermelhos distroférricos ${ }^{(2)}$ & A & 25,00 & 50,87 & 19,87 & 29,27 & 0,021 & 2,68 & 0,93 & 0,46 \\
\hline Latossolos Vermelhos distroférricos ${ }^{(2)}$ & B & 120,00 & 54,26 & 18,90 & 24,84 & 0,008 & 2,77 & 1,03 & 0,47 \\
\hline Latossolos Vermelhos distróficos ${ }^{(1)}$ & A & 10,00 & 8,00 & 9,00 & 83,00 & 0,016 & 2,58 & 1,14 & 0,17 \\
\hline Latossolos Vermelhos distróficos ${ }^{(1)}$ & B & 300,00 & 23,00 & 12,00 & 65,00 & 0,006 & 2,64 & 1,17 & 0,24 \\
\hline Latossolos Vermelhos eutroférricos ${ }^{(2)}$ & A & 25,00 & 48,50 & 18,00 & 33,50 & 0,018 & 2,70 & 1,47 & 0,34 \\
\hline Latossolos Vermelhos eutroférricos ${ }^{(2)}$ & B & 100,00 & 58,67 & 14,00 & 27,33 & 0,006 & 2,70 & 1,37 & 0,38 \\
\hline Luvissolos Crômicos órticos ${ }^{(3)}$ & A & 43,00 & 16,48 & 21,59 & 61,94 & 0,015 & 2,62 & 1,54 & 0,25 \\
\hline Luvissolos Crômicos órticos ${ }^{(3)}$ & $\mathrm{C}$ & 140,00 & 18,51 & 13,01 & 28,47 & 0,003 & 2,62 & 1,54 & 0,33 \\
\hline Luvissolos Crômicos pálicos ${ }^{(3)}$ & A & 18,00 & 8,00 & 7,00 & 85,00 & 0,007 & 2,63 & 1,39 & 0,16 \\
\hline Luvissolos Crômicos pálicos ${ }^{(3)}$ & B & 260,00 & 21,20 & 8,00 & 70,80 & 0,002 & 2,67 & 1,53 & 0,20 \\
\hline Neossolos Flúvicos Ta eutróficos ${ }^{(2)}$ & A & 17,00 & 41,00 & 28,00 & 31,00 & 0,012 & 2,66 & 1,42 & 0,35 \\
\hline Neossolos Flúvicos Ta eutróficos ${ }^{(2)}$ & $\mathrm{C}$ & 100,00 & 39,00 & 28,50 & 32,50 & 0,004 & 2,67 & 1,41 & 0,35 \\
\hline Neossolos Litólicos distróficos ${ }^{(1)}$ & A & 30,00 & 11,43 & 30,43 & 58,13 & 0,014 & 2,67 & 1,30 & 0,29 \\
\hline Neossolos Litólicos distróficos ${ }^{(1)}$ & $\mathrm{C}$ & 50,00 & 7,00 & 51,30 & 41,70 & 0,005 & 2,70 & 1,58 & 0,31 \\
\hline Neossolos Litólicos eutróficos ${ }^{(2)}$ & A & 60,00 & 30,09 & 29,21 & 38,99 & 0,021 & 2,55 & 1,28 & 0,34 \\
\hline Neossolos Litólicos eutróficos ${ }^{(2)}$ & $\mathrm{C}$ & 20,00 & 13,70 & 22,60 & 63,70 & 0,007 & 2,70 & 1,58 & 0,25 \\
\hline Neossolos Quartzarênicos hidromórficos ${ }^{(2)}$ & A & 28,00 & 22,13 & 18,37 & 59,50 & 0,013 & 2,63 & 1,43 & 0,26 \\
\hline Neossolos Quartzarênicos hidromórficos ${ }^{(2)}$ & $\mathrm{C}$ & 170,00 & 6,25 & 5,63 & 88,13 & 0,003 & 2,62 & 1,51 & 0,14 \\
\hline Neossolos Quartzarênicos órticos ${ }^{(1)}$ & A & 50,00 & 4,73 & 3,88 & 91,39 & 0,007 & 2,66 & 1,42 & 0,08 \\
\hline Neossolos Quartzarênicos órticos ${ }^{(1)}$ & $\mathrm{C}$ & 200,00 & 6,74 & 5,54 & 87,73 & 0,002 & 2,66 & 1,50 & 0,14 \\
\hline Neossolos Regolíticos distróficos ${ }^{(2)}$ & A & 20,00 & 16,00 & 46,00 & 38,00 & 0,010 & 2,70 & 1,40 & 0,36 \\
\hline Neossolos Regolíticos distróficos ${ }^{(2)}$ & $\mathrm{C}$ & 70,00 & 8,50 & 61,00 & 30,50 & 0,001 & 2,70 & 1,58 & 0,32 \\
\hline
\end{tabular}


Tabela 1. Continuação...

\begin{tabular}{|c|c|c|c|c|c|c|c|c|c|}
\hline \multirow[t]{2}{*}{ Classe de solo } & \multirow[t]{2}{*}{ Horizonte } & $\begin{array}{l}\text { Espessura } \\
(\mathrm{cm})^{(4)}\end{array}$ & Argila & Silte & Areia & \multirow[t]{2}{*}{$\begin{array}{c}\mathrm{OC} \\
\left(\mathrm{g} \mathrm{g}^{-1}\right)^{(5)}\end{array}$} & $\begin{array}{c}\text { Densidade de } \\
\text { Partículas }\end{array}$ & $\begin{array}{c}\text { Densidade } \\
\text { do Solo }\end{array}$ & \multirow{2}{*}{$\begin{array}{c}\text { Umidade } \\
\text { na CC } \\
\left(\mathrm{cm}^{3} \mathrm{~cm}^{-3}\right)\end{array}$} \\
\hline & & & \multicolumn{3}{|c|}{-------- $(\%)^{(4)}$--------- } & & -------- $(\mathrm{g} \mathrm{cn}$ & $\left.n^{-3}\right)$-------- & \\
\hline Nitossolos Vermelhos distróficos ${ }^{(2)}$ & A & 20,00 & 42,60 & 31,70 & 25,70 & 0,014 & 2,59 & 0,97 & 0,46 \\
\hline Nitossolos Vermelhos distróficos ${ }^{(2)}$ & B & 200,00 & 52,37 & 28,28 & 19,35 & 0,004 & 2,67 & 1,22 & 0,45 \\
\hline Nitossolos Vermelhos eutróficos ${ }^{(1)}$ & A & 25,00 & 39,35 & 41,25 & 19,40 & 0,025 & 2,80 & 1,16 & 0,46 \\
\hline Nitossolos Vermelhos eutróficos ${ }^{(1)}$ & B & 140,00 & 65,73 & 19,33 & 14,93 & 0,005 & 2,87 & 1,16 & 0,51 \\
\hline Planossolos Háplicos distróficos ${ }^{(3)}$ & A & 50,00 & 20,33 & 52,70 & 26,97 & 0,032 & 2,70 & 1,57 & 0,33 \\
\hline Planossolos Háplicos distróficos ${ }^{(3)}$ & B & 160,00 & 34,35 & 42,09 & 23,55 & 0,005 & 2,70 & 1,95 & 0,24 \\
\hline Planossolos Háplicos eutróficos ${ }^{(3)}$ & A & 110,00 & 6,17 & 12,90 & 80,94 & 0,009 & 2,70 & 1,57 & 0,19 \\
\hline Planossolos Háplicos eutróficos ${ }^{(3)}$ & B & 160,00 & 27,94 & 15,33 & 53,88 & 0,002 & 2,70 & 1,95 & 0,20 \\
\hline Planossolos Nátricos órticos ${ }^{(2)}$ & A & 30,00 & 11,75 & 31,75 & 54,00 & 0,011 & 2,67 & 1,71 & 0,25 \\
\hline Planossolos Nátricos órticos ${ }^{(2)}$ & B & 140,00 & 34,50 & 29,75 & 35,75 & 0,004 & 2,62 & 2,15 & 0,21 \\
\hline Plintossolos Háplicos distróficos ${ }^{(2)}$ & A & 42,00 & 52,77 & 24,63 & 22,60 & 0,021 & 2,61 & 1,52 & 0,35 \\
\hline Plintossolos Háplicos distróficos ${ }^{(2)}$ & B & 150,00 & 63,93 & 14,70 & 21,37 & 0,002 & 2,64 & 1,33 & 0,41 \\
\hline Plintossolos Pétricos concrecionários ${ }^{(1)}$ & A & 35,00 & 13,00 & 29,10 & 57,90 & 0,009 & 2,64 & 1,47 & 0,27 \\
\hline Plintossolos Pétricos concrecionários ${ }^{(1)}$ & B & 105,00 & 21,68 & 35,32 & 43,00 & 0,003 & 2,64 & 1,53 & 0,30 \\
\hline Vertissolos Ebânicos órticos ${ }^{(3)}$ & A & 15,00 & 70,00 & 22,00 & 8,00 & 0,009 & 2,53 & 2,15 & 0,21 \\
\hline Vertissolos Ebânicos órticos ${ }^{(3)}$ & $\mathrm{C}$ & 140,00 & 22,00 & 18,00 & 60,00 & 0,001 & 2,49 & 2,13 & 0,16 \\
\hline Vertissolos Háplicos órticos ${ }^{(3)}$ & A & 20,00 & 54,00 & 38,90 & 7,10 & 0,026 & 2,70 & 1,21 & 0,48 \\
\hline Vertissolos Háplicos órticos ${ }^{(3)}$ & $\mathrm{C}$ & 140,00 & 69,40 & 26,33 & 4,28 & 0,004 & 2,70 & 1,24 & 0,49 \\
\hline
\end{tabular}

${ }^{(1)}$ Dados provenientes de perfis com classificação igual à classe apresentada no mapa de solos e localizados no bioma Cerrado. ${ }^{(2)}$ Dados provenientes de perfis localizados no bioma Cerrado. ${ }^{\left({ }^{3}\right)}$ Dados provenientes de perfis localizados em outros biomas. ${ }^{(4)}$ Fonte: Oliveira et al. (2008). ${ }^{(5)}$ Fonte: Cooper et al. (2005). CC, capacidade de campo.

diferentes características climáticas e de cobertura da terra de outros biomas (Demattê \& Demattê, 1993).

As classes de solos que apresentaram maiores teores de argila foram Vertissolos, Nitossolos e Gleissolos. Quanto aos teores de areia, a classe de solo com maiores valores foi Neossolos Quartzarênicos. Essas informações estão em concordância com Santos et al. (2006). Os maiores valores médios de OC foram observados nos Chernossolos e Gleissolos, o que também está de acordo com Gebler et al. (2005) e Santos et al. (2006).

Ressalta-se que os valores de FC obtidos devem ser utilizados com maior restrição, uma vez que há a propagação de erros, nas diferentes etapas da metodologia para sua obtenção (Budiman et al., 2003).

As maiores profundidades estimadas do lençol freático ocorreram em áreas próximas a divisores hidrográficos (Figura 1) ou em áreas com padrão de drenagem paralelo. Em Mingoti (2012), que utilizou metodologia semelhante à deste estudo, os maiores valores de profundidade do lençol freático foram obtidos nas áreas próximas aos divisores de água. Entretanto, valores altos de profundidade, estimados em regiões com padrão de drenagem paralelo, não foram observados em outros trabalhos (Mingoti, 2012; Nobre et al., 2011), o que pode ser uma limitação do método adotado aqui.
Os menores valores de recargas hídricas líquidas estimadas para a área de estudo encontram-se próximos ao litoral do Piauí e na porção leste da Bahia (Figura 2), que são mais próximas ao bioma Caatinga, enquanto os maiores valores são encontrados nas áreas do Mato Grosso, próximas ao bioma Amazônia. Esses resultados corroboram os de Alvares et al. (2013).

Como se pode observar, pela análise das equações para obtenção de $\mathrm{RF}_{\mathrm{QO}} \mathrm{e} \mathrm{TR}$, as áreas mais susceptíveis à contaminação (menores valores do índice TR) devem contemplar: valores mínimos de profundidade do lençol freático, densidade global e teor de carbono orgânico do solo; e valores máximos de recarga hídrica líquida.

A classe de solos com menores valores de TR - que representam áreas mais susceptíveis à contaminação do lençol freático - estão localizadas na região Sudeste do Mato Grosso (Figura 3), predominantemente nas áreas com lençol freático pouco profundo e com Neossolos Quartzarênicos órticos, e, também, nas regiões Oeste da Bahia, Sudoeste de Goiás, Norte de Mato Grosso do Sul e Centro-leste e Centro-oeste de Mato Grosso, áreas onde também há lençol freático pouco profundo, mas com ocorrência de Latossolos Vermelhos distróficos e Neossolos Quartzarênicos órticos. Essas áreas apresentam valores de TR inferiores a 1 ano 
e são consideradas como de maior prioridade para ações de ordenamento e fiscalização do uso correto de agrotóxicos e para o monitoramento da qualidade das águas, não apenas quanto a agrotóxicos, mas também quanto à contaminação microbiana (Washington, 2010).
Sugere-se, ainda, verificar se as áreas com maior vulnerabilidade, apresentadas na Figura 3, coincidem com aquíferos não confinados utilizados para abastecimento público, pois uma eventual contaminação desses recursos hídricos poderia afetar a saúde dos habitantes dessas áreas (Dores et al., 2008).

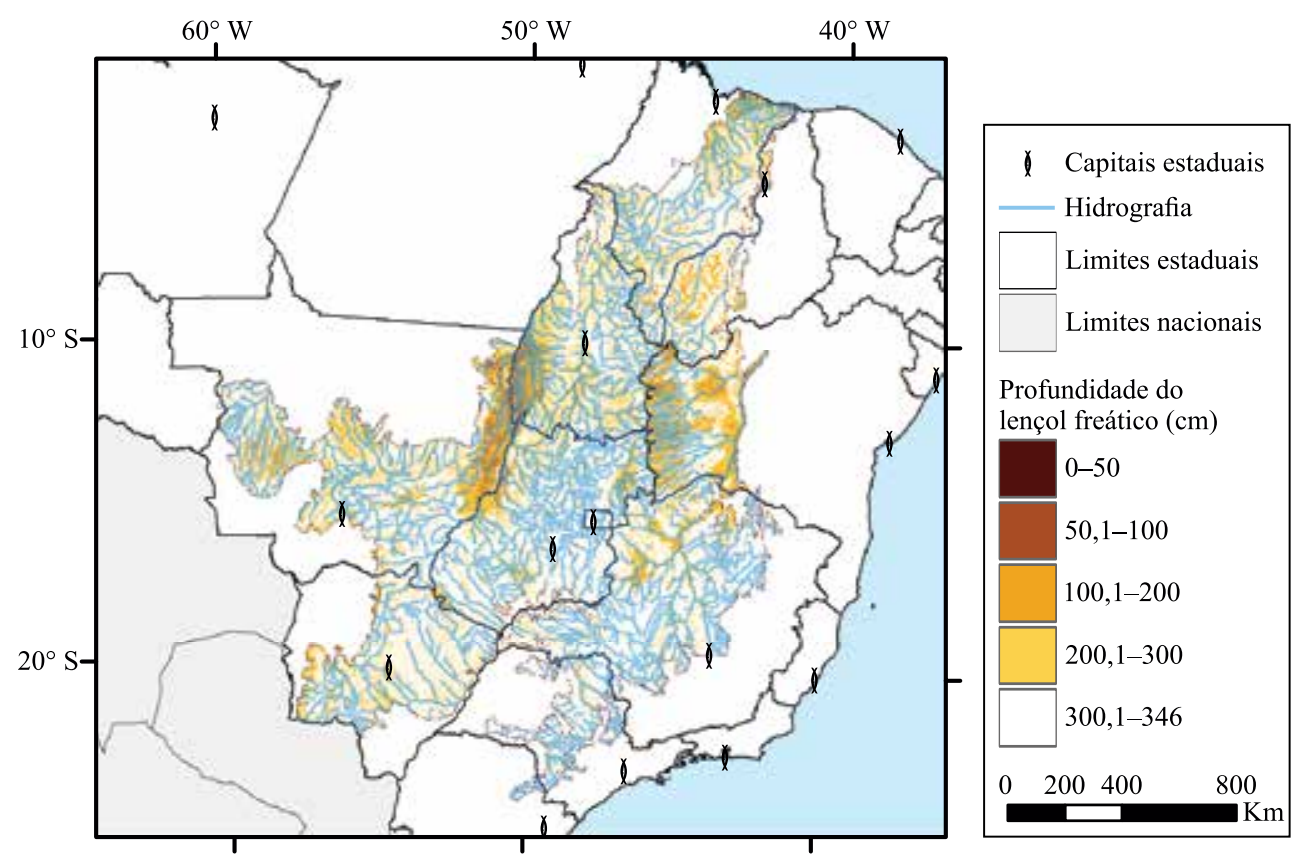

Figura 1. Profundidade estimada do lençol freático na área de estudo. Fonte: Região do bioma Cerrado no Brasil (IBGE, 2004), Base Territorial (IBGE, 2007) e Hidrografia (ANA, 2015).
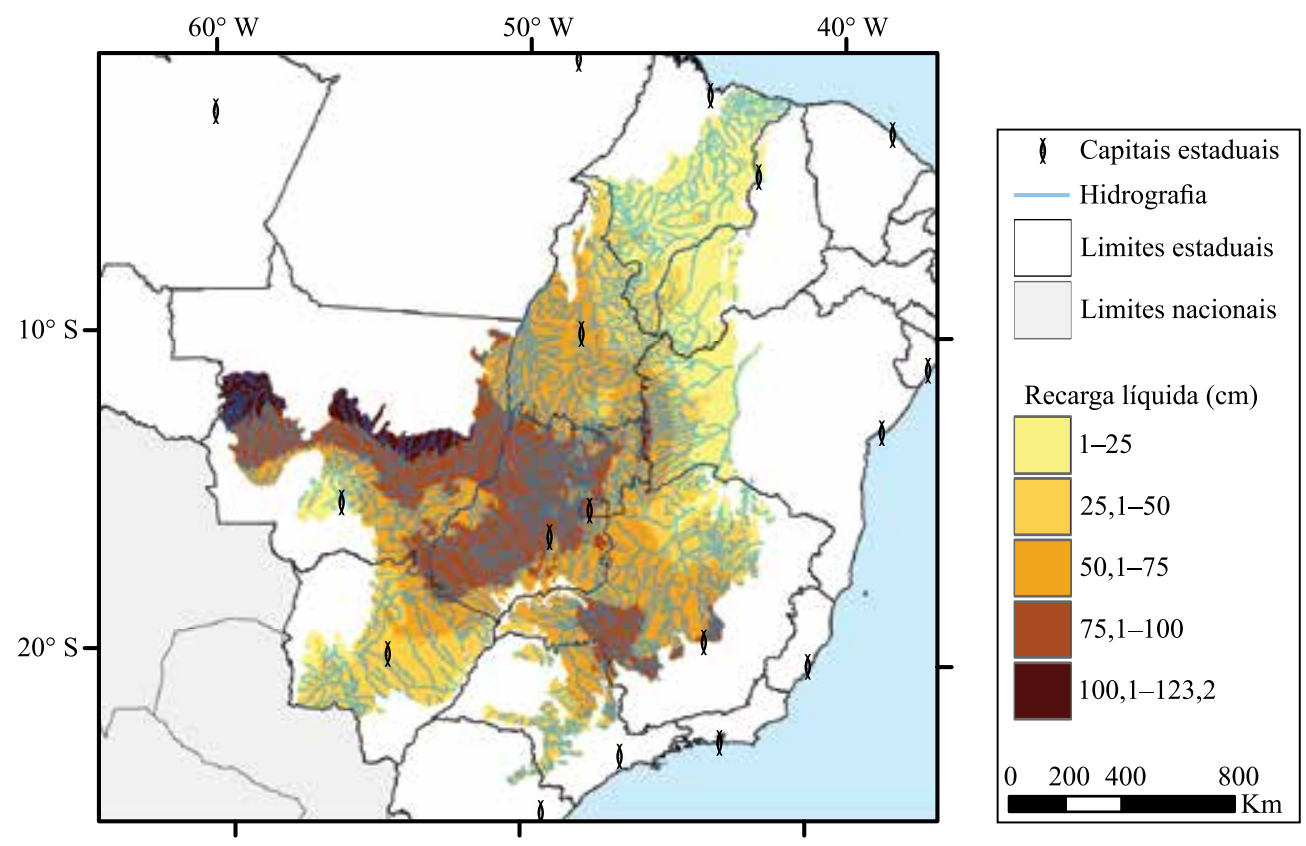

Figura 2. Diferença entre as médias históricas de chuva e evapotranspiração no período de outubro a março para a área de estudo. Fonte: Região do bioma Cerrado no Brasil (IBGE, 2004); Base Territorial (IBGE, 2007); Hidrografia (ANA, 2015). 


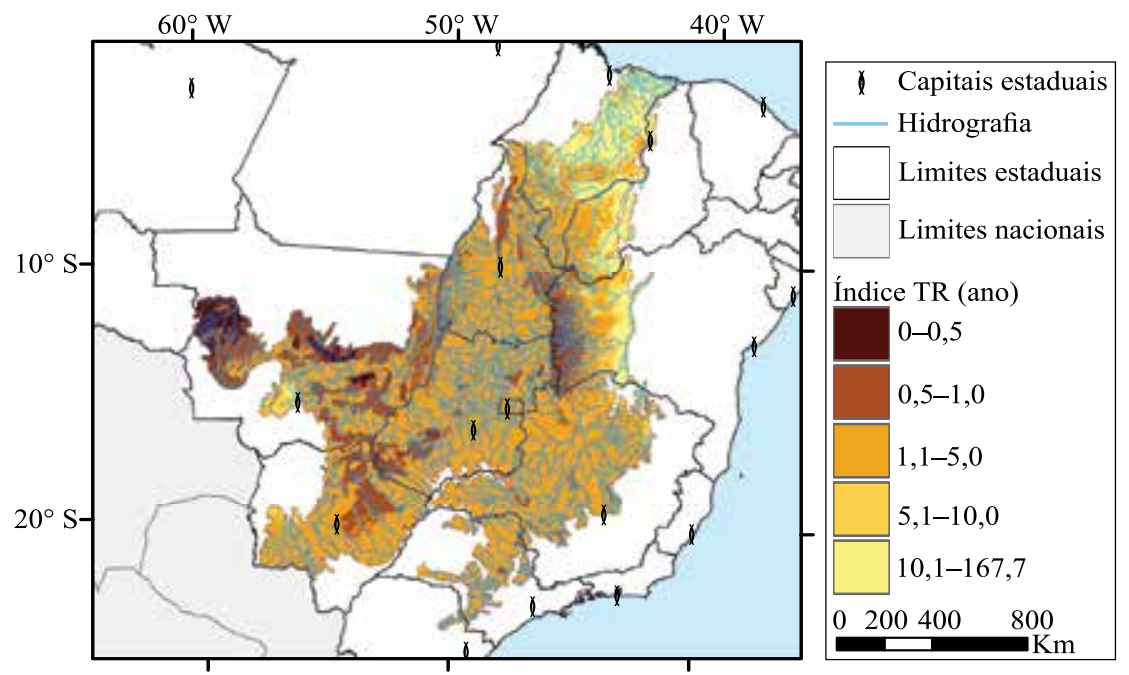

Figura 3. Distribuição de classes do índice TR para o bioma Cerrado. Fonte: Região do bioma Cerrado no Brasil (IBGE, 2004); Base Territorial (IBGE, 2007); Hidrografia (ANA, 2015).

Tabela 2. Proporção dos solos na área do Cerrado (\%) discriminada conforme diferentes classes do índice TR em anos $(\leq 0,5,0,51$ a $1,00,1,01$ a $5,00,5,01$ a $10,00,>10$ anos $)$.

\begin{tabular}{|c|c|c|c|c|c|c|}
\hline \multirow[t]{2}{*}{ Classe de solo } & \multicolumn{5}{|c|}{ Proporção dos solos na área do Cerrado (\%) } & \multirow[t]{2}{*}{ Soma } \\
\hline & $\leq 0,5$ & 0,51 a 1,00 & 1,01 a 5,00 & 5,01 a 10,00 & $>10$ & \\
\hline Argissolos Vermelho-Amarelos distróficos & 0,16 & 0,39 & 4,77 & 0,35 & 0,20 & 5,87 \\
\hline Argissolos Vermelho-Amarelos eutróficos & 0,04 & 0,01 & 0,87 & 0,19 & 1,04 & 2,16 \\
\hline Argissolos Vermelhos distróficos & 0,02 & 0,04 & 0,97 & 0,00 & 0,00 & 1,03 \\
\hline Argissolos Vermelhos eutróficos & 0,07 & 0,00 & 2,45 & 0,26 & 0,04 & 2,82 \\
\hline Cambissolos Háplicos Ta eutróficos & 0,04 & 0,02 & 0,52 & 0,53 & 0,30 & 1,40 \\
\hline Cambissolos Háplicos Tb distróficos & 0,14 & 0,23 & 7,28 & 0,15 & 0,01 & 7,81 \\
\hline Cambissolos Húmicos distróficos & 0,00 & 0,00 & 0,08 & 0,00 & 0,00 & 0,09 \\
\hline Chernossolos Argilúvicos órticos & 0,01 & 0,01 & 0,33 & 0,01 & 0,00 & 0,35 \\
\hline Chernossolos Rêndzicos órticos & 0,01 & 0,00 & 0,17 & 0,06 & 0,00 & 0,23 \\
\hline Gleissolos Háplicos Tb distróficos & 0,20 & 0,12 & 1,18 & 0,02 & 0,04 & 1,56 \\
\hline Gleissolos Sálicos sódicos & 0,01 & 0,00 & 0,00 & 0,00 & 0,07 & 0,09 \\
\hline Latossolos Amarelos distróficos & 0,59 & 1,38 & 5,12 & 1,83 & 2,54 & 11,47 \\
\hline Latossolos Vermelho-Amarelos distroférricos & 0,00 & 0,00 & 0,05 & 0,00 & 0,00 & 0,06 \\
\hline Latossolos Vermelho-Amarelos distróficos & 0,47 & 1,12 & 7,67 & 0,23 & 0,11 & 9,59 \\
\hline Latossolos Vermelhos distroférricos & 0,08 & 0,09 & 3,81 & 0,05 & 0,00 & 4,03 \\
\hline Latossolos Vermelhos distróficos & 0,19 & 2,65 & 12,36 & 0,08 & 0,00 & 15,28 \\
\hline Latossolos Vermelhos eutroférricos & 0,00 & 0,00 & 0,12 & 0,00 & 0,00 & 0,12 \\
\hline Luvissolos Crômicos órticos & 0,00 & 0,00 & 0,03 & 0,01 & 0,03 & 0,08 \\
\hline Luvissolos Crômicos pálicos & 0,00 & 0,00 & 0,26 & 0,05 & 0,00 & 0,32 \\
\hline Neossolos Flúvicos Ta eutróficos & 0,03 & 0,01 & 0,13 & 0,08 & 0,31 & 0,56 \\
\hline Neossolos Litólicos distróficos & 0,21 & 0,19 & 5,36 & 0,84 & 0,98 & 7,59 \\
\hline Neossolos Litólicos eutróficos & 0,01 & 0,01 & 0,30 & 0,09 & 0,02 & 0,42 \\
\hline Neossolos Quartzarênicos hidromórficos & 0,11 & 0,27 & 0,12 & 0,01 & 0,11 & 0,61 \\
\hline Neossolos Quartzarênicos órticos & 2,57 & 6,45 & 4,44 & 0,15 & 0,76 & 14,37 \\
\hline Neossolos Regolíticos distróficos & 0,01 & 0,00 & 0,17 & 0,05 & 0,00 & 0,23 \\
\hline Nitossolos Vermelhos distróficos & 0,01 & 0,00 & 0,01 & 0,28 & 0,08 & 0,38 \\
\hline Nitossolos Vermelhos eutróficos & 0,00 & 0,00 & 0,22 & 0,04 & 0,00 & 0,27 \\
\hline Planossolos Háplicos distróficos & 0,01 & 0,00 & 0,19 & 0,00 & 0,00 & 0,20 \\
\hline Planossolos Háplicos eutróficos & 0,01 & 0,01 & 0,03 & 0,05 & 0,07 & 0,17 \\
\hline Planossolos Nátricos órticos & 0,02 & 0,00 & 0,36 & 0,01 & 0,02 & 0,42 \\
\hline Plintossolos Háplicos distróficos & 0,58 & 0,43 & 2,53 & 0,16 & 0,36 & 4,06 \\
\hline Plintossolos Pétricos concrecionários & 0,20 & 0,59 & 3,78 & 0,30 & 1,40 & 6,27 \\
\hline Vertissolos Ebânicos órticos & 0,00 & 0,00 & 0,03 & 0,01 & 0,00 & 0,05 \\
\hline Vertissolos Háplicos órticos & 0,00 & 0,00 & 0,00 & 0,00 & 0,03 & 0,03 \\
\hline Soma $(\%)$ & 5,81 & 14,03 & 65,76 & 5,88 & 8,52 & 100,00 \\
\hline
\end{tabular}


As proporções de solos do Cerrado discriminadas quanto às diferentes classes de índice TR estão apresentadas na Tabela 2. Valores de TR menores ou iguais a 0,50 ano ocorrem em 5,81\% da área do Cerrado; valores entre 0,51 e 1,00 ano, em $14,03 \%$ da área; valores entre 1,01 e 5,00 anos, em 65,75\% da área; valores entre 5,01 e 10,00 anos, em 5,88\% da área; e valores acima de 10 anos, em 8,52\% da área. Medidas para maior proteção quanto à contaminação devem ser adotadas especialmente nas áreas com valor de TR menores ou iguais a 0,50 ano (Washington, 2010).

\section{Conclusões}

1. A filtragem adotada para a obtenção dos dados de entrada para determinação do índice TR é satisfatória para uma análise em escala exploratória; entretanto, há a necessidade de estudos para validação dos valores obtidos.

2. A utilização do modelo Hand para estimar a profundidade do lençol freático de maneira espacializada para a área de estudo é promissora; entretanto, a avaliação de sua acurácia ainda depende da comparação com dados de campo.

3. O índice TR possibilita a caracterização, em base territorial, das regiões mais susceptíveis à contaminação do lençol freático.

4. As áreas mais susceptíveis à contaminação das águas subterrâneas estão localizadas nas regiões Sudeste e Centro-leste do Mato Grosso, Oeste da Bahia, Sudoeste de Goiás e Norte de Mato Grosso do Sul, onde se sugere que sejam priorizadas ações de gerenciamento do uso de agrotóxicos.

\section{Referências}

ALVARES, C.A.; MATTOS, E.M. de; SENTELHAS, P.C.; MIRANDA, A.C.; STAPE, J.L. Modeling temporal and spatial variability of leaf wetness duration in Brazil. Theoretical and Applied Climatology, v.120, p.455-467, 2015. DOI: 10.1007/ s00704-014-1182-3.

ALVARES, C.A.; STAPE, J.L.; SENTELHAS, P.C.; DE MORAES, G.; LEONARDO, J.; SPAROVEK, G. Köppen's climate classification map for Brazil. Meteorologische Zeitschrift, v.22, p.711-728, 2013. DOI: 10.1127/0941-2948/2013/0507.

ANA. Agência Nacional de Águas. Bases de dados georreferenciadas: Rede Hidrográfica Codificada. Disponível em: $<$ http://www.ana.gov.br/bibliotecavirtual/solicitacaoBaseDados. asp>. Acesso em: 4 maio 2015.

BROLlO, M.J.; VEDOVELLO, R.; ODA, G.H. Avaliação da vulnerabilidade natural de aquíferos à contaminação através de um sistema gerenciador de informações geoambientais
- Um instrumento de gestão ambiental. In: CONGRESSO INTERAMERICANO DE ENGENHARIA SANITÁRIA E AMBIENTAL, 27., 2000, Porto Alegre. [Anais]. São Paulo: AIDIS; Rio de Janeiro: ABES, 2000.

BUDIMAN, M.; MCBRATNEY, A.b.; MENDONÇA-SANTOS, M. de L.; SANTOS, H.G. dos. Revisão sobre funções de pedotransferência (PTFS) e novos métodos de predição de classes e atributos do solo. Rio de Janeiro: Embrapa Solos, 2003. 50p. (Embrapa Solos. Documentos, 45).

COOPER, M.; MENDES, L.M.S.; SILVA, W.L.C.; SPAROVEK, G. A national soil profile database for Brazil available to international scientists. Soil Science Society of America Journal, v.69, p.649-652. DOI: 10.2136/sssaj2004.0140.

DAVIDSON, J.M.; RIECK, C.E.; SANTELMANN, P.W. Influence of water flux and porous material on the movement of selected herbicides. Soil Science Society of America Journal, v.32, p.629633, 1968. DOI: 10.2136/sssaj1968.03615995003200050017x.

DELLAMATRICE, P.M.; MONTEIRO, R.T.R. Principais aspectos da poluição de rios brasileiros por pesticidas. Revista Brasileira de Engenharia Agrícola e Ambiental, v.18, p.12961301, 2014. DOI: 10.1590/1807-1929/agriambi.v18n12p1296-1301.

DEMATTÊ, J.L.I.; DEMATTÊ, J.A.M. Comparações entre as propriedades químicas de solos das regiões da floresta Amazônica e do Cerrado do Brasil Central. Scientia Agrícola, v.50, p.272286, 1993. DOI: 10.1590/S0103-90161993000200016.

DORES, E.F.G.C.; CARBO, L.; RIBEIRO, M.L.; DELAMONICA-FREIRE, E.M. Pesticide levels in ground and surface waters of Primavera do Leste Region, Mato Grosso, Brazil. Journal of Chromatographic Science, v.46, p.585-590, 2008. DOI: 10.1093/chromsci/46.7.585.

FOSTER, S.S.D.; HIRATA, R.C.; ROCHA, G.A. Riscos de poluição de águas subterráneas; uma proposta de avaliação regional. São Paulo: ABAS, 1988. Disponível em: <http://www. bvsde.ops-oms.org/muwww/fulltext/repind46/riscos/riscos. html>. Acesso em: 29 jun. 2015.

FOSTER, S.; HIRATA, R.; GOMES, D.; D'ELIA, M.; PARIS, $M$. Groundwater quality protection: a guide for water service companies, municipal authorities and environment agencies, Washington: The World Bank, 2002. 103p. DOI: 10.1596/0-82134951-1.

FUTCH, S.H.; SINGH, M. Herbicide mobility using soil leaching columns. Bulletin of Environmental Contamination and Toxicology, v.62, p.520-529, 1999. DOI: 10.1007/s001289900907.

GEBLER, L.; GOMES, M.A.F.; SPADOTTO, C.A. Banco de Dados com algumas propriedades de solos do Brasil para aplicação em modelagem matemática de agroquímicos e seus resíduos junto à fruticultura temperada. Bento Gonçalves: Embrapa Uva e Vinho, 2005. 11p. (Embrapa Uva e Vinho. Comunicado técnico, 66).

GOEDERT, W.J. (Ed.). Solos dos Cerrados: tecnologias e estratégias de manejo. Planaltina: Embrapa-CPAC; São Paulo: Nobel, 1987. 442p.

GOMES, M.A.F.; SPADOTTO, C.A.; PEREIRA, A.S.; MATALLO, M.B.; LUCHINI, L.C. Movimento do herbicida 
tebutiuron em dois solos representativos das áreas de recarga do aquífero Guarani. Revista Brasileira de Engenharia Agrícola e Ambiental, v.10, p.479-483, 2006. DOI: 10.1590/S141543662006000200032 .

HIRATA, R.; ZOBY, J.L.G.; OLIVEIRA, F.R. de. Água subterrânea: reserva estratégica ou emergencial. In: BICUDO, C.E. de M.; TUNDISI, J.G.; SCHEUENSTUHL, M.C.B. (Org.). Águas do Brasil: análises estratégicas. São Paulo: Instituto de Botânica, 2010. p.149-161.

IBGE. Instituto Brasileiro de Geografia e Estatística. Mapa de biomas do Brasil: escala 1:5.000.000. 2004. Disponível em: $<$ http://mapas.ibge.gov.br/biomas2/viewer.htm>. Acesso em: 4 maio 2015.

IBGE. Instituto Brasileiro de Geografia e Estatística. Base cartográfica 2007. 2007. Disponível em: <http://mapas.ibge. gov.br/bases-e-referenciais/bases-cartograficas/malhas-digitais. html>. Acesso em: 4 maio 2015.

KEESSTRA, S.D.; GEISSEN, V.; MOSSE, K.; PIIRANEN, S.; SCUDIERO, E.; LEISTRA, M.; SCHAIK, L. van. Soil as a filter for groundwater quality. Current Opinion in Environmental Sustainability, v.4, p.507-516, 2012. DOI: 10.1016/j. cosust.2012.10.007.

KIEHL, E.J. Manual de edafologia: relações solo-planta. São Paulo: Agronômica Ceres, 1979. 264p.

MINGOTI, R. Efeitos da espacialização da cobertura florestal e da profundidade dos solos na produção de água de uma bacia hidrográfica. 2012. 170p. Tese (Doutorado) - Universidade de São Paulo, Piracicaba. DOI: 10.11606/t.11.2012.tde-25102012090126.

NAIME, J. de M.; VAZ, C.M.P.; MACEDO, A. Determinações físicas do solo a partir da granulometria: programa Qualisolo. In: REUNIÃO BRASILEIRA DE MANEJO E CONSERVAÇÃO DO SOLO E DA ÁGUA, 16., 2006, Aracaju. Novos desafios do carbono no manejo conservacionista. Resumos. Aracaju: Sociedade Brasileira de Ciência do Solo, 2006. 1 CD-ROM. 5p.

NOBRE, A.D.; CUARTAS, L.A.; HODNETT, M.G.; RENNÓ, C.D.; RODRIGUES, G.; SILVEIRA, A.; WATERLOO, M.; SALESKA, S. Height Above the Nearest Drainage - a hydrologically relevant new terrain model. Jornal of Hydrology, v. 404, p.13-29, 2011. DOI: 10.1016/j.jhydrol.2011.03.051.

OLIVEIRA, S.R. de M.; ZURMELY, H.R.; LIMA JÚNIOR, F.A. de; SANTOS, H.G. dos; MEIRELLES, M.P.S. Sistema de informação de solos brasileiros. Campinas: Embrapa Informática Agropecuária, 2008. 8p. (Embrapa Informática Agropecuária. Comunicado técnico, 93).
RACKE, K.D.; SKIDMORE, M.W.; HAMILTON, D.J.; UNSWORTH, J.B.; MIYAMOTO, J.; COHEN, S.Z. Biocide fate in tropical soil (Technical Report). Pure and Applied Chemistry, v.69, p.1349-1371, 1997. DOI: 10.1351/pac199769061349.

RAO, P.S.C., HORNSBY, A.G.; JESSUP, R.E. Indices for ranking the potential for pesticide contamination of groundwater. Proceedings Soil and Crop Science Society of Florida, v.44, p.1-8, 1985.

SANTOS, H.G. dos; JACOMINE, P.K.T.; ANJOS, L.H.C. dos; OLIVEIRA, V.A. de; OLIVEIRA, J.B. de; COELHO, M.R.; LUMBRERAS, J.F.; CUNHA, T.J.F. (Ed.). Sistema brasileiro de classificação de solos. 2.ed. Rio de Janeiro: Embrapa Solos, 2006. 306p.il.

SANTOS, H.G. dos; CARVALHO JÚNIOR, W. de; DART, R. de O.; ÁGLIO, M.L.D.; SOUZA, J.S. de; PARES, J.G.; FONTANA, A.; MARTINS, A.L. da S.OLIVEIRA, A.P. de. O novo mapa de solos do Brasil: legenda atualizada. Rio de Janeiro: Embrapa Solos, 2011.

SOUZA, N.A. de. Vulnerabilidade à poluição das águas subterrâneas: um estudo do Aquífero Bauru na zona urbana de Araguari, MG. 2009. 135p. Dissertação (Mestrado) Universidade Federal de Uberlândia, Uberlândia.

SPADOTTO, C.A.; GOMES, M.A.F. Resíduos de Agroquímicos no Ambiente. In: SPADOTTO, C.A.; RIBEIRO, W.C. Gestão de resíduos na agricultura e agroindústria. Botucatu: FEPAF, 2006. p.302-319.

SPADOTTO, C.A.; HOLLER, W.A.; MARTINHO, P.R.R.; FOIS, N.S.; MORAES, D.A. de C.; DALTIO, J.; TRAJANO, S.R. da S. Interfaces de modelos ambientais e sistemas de informação geográfica para a gestão territorial da contaminação de recursos hídricos. Campinas: Embrapa Gestão Territorial, 2012. 37p. (Embrapa Gestão Territorial. Documentos, 1).

TOMASELLA, J.; HODNETT, M.G.; ROSSATO, L. Pedotransfer functions for the estimation of soil water retention in Brazilian soils. Soil Soil Science Society of America Journal, v.64, p.327338, 2000. DOI: 10.2136/sssaj2000.641327x.

WASHINGTON (State). Department of Health. Wellhead Protection Program Guidance Document. Olympia: Washington State Department of Health, 2010. DOH 331-018 (revised).

WEBER, J.B.; WEED, S.B. Effects of soil on the biological activity of pesticides. In: GUENZI, W.D. (Ed.). Pesticides in soil and water. Madison: Soil Science Society of America, 1974. p.223-256. DOI: 10.2136/1974.pesticides.c10.

Recebido em 31 de agosto de 2015 e aprovado em 6 de junho de 2016

Pesq. agropec. bras., Brasília, v.51, n.9, p.1252-1260, set. 2016

DOI: 10.1590/S0100-204X2016000900025 